Portland State University

PDXScholar

Summer 7-31-2012

\title{
The Effects of Yoga Therapy on the Quality of Life for a Paraplegic Individual
}

Allison Renee Purdy

Portland State University

Follow this and additional works at: https://pdxscholar.library.pdx.edu/open_access_etds

Part of the Movement and Mind-Body Therapies Commons, and the Musculoskeletal, Neural, and Ocular Physiology Commons

Let us know how access to this document benefits you.

\section{Recommended Citation}

Purdy, Allison Renee, "The Effects of Yoga Therapy on the Quality of Life for a Paraplegic Individual" (2012). Dissertations and Theses. Paper 342.

https://doi.org/10.15760/etd.342

This Thesis is brought to you for free and open access. It has been accepted for inclusion in Dissertations and Theses by an authorized administrator of PDXScholar. Please contact us if we can make this document more accessible: pdxscholar@pdx.edu. 
The Effects of Yoga Therapy on the Quality of Life for a Paraplegic Individual

by

\begin{abstract}
Allison Renee Purdy
A thesis submitted in partial fulfillment of the requirements for the degree of

Master of Science

in

Health Studies
\end{abstract}

Thesis Committee:

Gary Brodowicz, Chair

Claire Wheeler

Susan Palmiter

Portland State University

2012 


\begin{abstract}
The purpose of this study was to document the effects that a regular yoga therapy practice has on the quality of life for a paraplegic individual. Due to the unique nature of spinal cord injury (SCI), this was a case study with one participant. For 5 weeks the subject practiced a standardized yoga routine three times a week with a yoga teacher, receiving private instruction. Interview questions were asked before and after the intervention to document the participant's quality of life. Each week, the subject completed a modified SF-36 questionnaire as well as Cohen's Perceived Stress Survey. Perceived pain and perceived stress were the two primary variables monitored in the study.

The results of this study demonstrated a slight reduction in perceived stress, a reduction in perceived pain, and an improvement in overall quality of life. Additionally, the subject increased her strength significantly from the beginning to the end of the study. Based on the findings in this study, it appears that a regular adapted yoga routine is beneficial for paraplegic individuals.
\end{abstract}




\section{DEDICATION}

For Becky, whose beautiful spirit has given me so much inspiration. My work is my blessing. 


\section{ACKNOWLEDGMENTS}

Thank you to Gary Brodowicz for helping this yogi navigate the world of science. Claire Wheeler and Susan Palmiter, many thanks for your support and knowledge, which helped to guide this study. 


\section{TABLE OF CONTENTS}

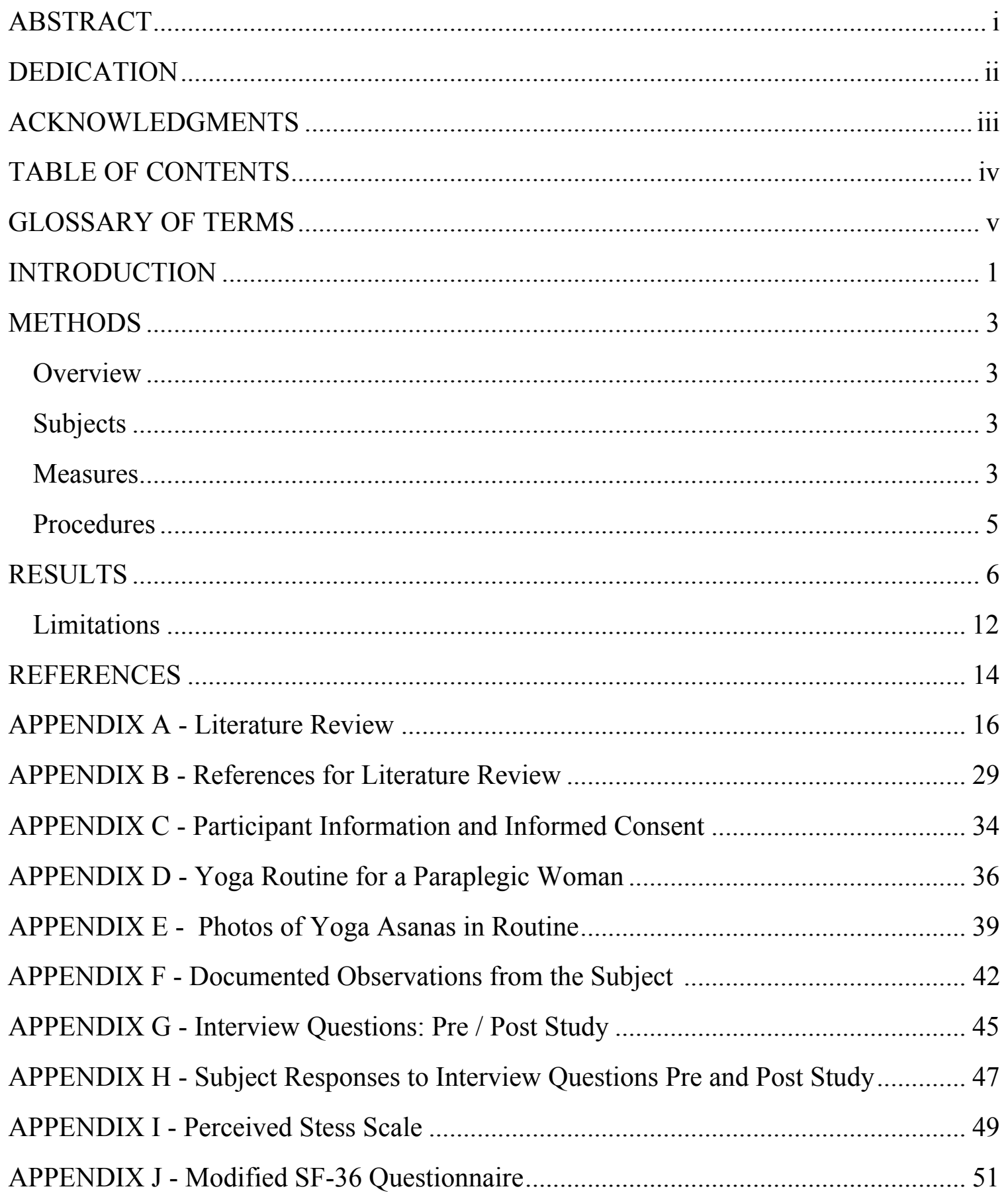




\section{GLOSSARY OF TERMS}

Asana - Sanskrit term which translates as "seat" is used to describe the hundreds of yoga poses in Hatha yoga. Each pose has a specific name incorporating the word asana. Yoga poses or asanas can be seated, standing, inverted, supine, prone, backbends or forward bends.

Meditation - Meditation is a practice of learning both how the mind works and also how to in turn work with the mind. Meditation can be an extended thought, a time of stillness, a time of reflection, a time of contemplation. Some of the effects that can be felt from meditation are stillness, clarity and relaxation.

Paralysis - The loss of the ability to move (and sometimes to feel anything) in part or most of the body, typically as a result of illness, poison, or injury. (paralysis, n.d.)

Paraplegic - A person with paralysis in both lower limbs due to injury of the spinal cord or disease.

Pranayama - Sanskrit term which translates as "breath control". Multiple forms of pranayama can be practiced by yoga practitioners to achieve a variety of results. Each type of breathing is intended to serve one specific function. They are not all the same.

Quadriplegic - A person with all four limbs affected by paralysis.

Yoga - Sanskrit term "to yoke", meaning to bring together. Originating in India, yoga is a system of postures "asanas", breathing "pranayama" and meditation. The intention of yoga is to bring the mind, body and spirit together in one union. It is not a religion. 


\section{INTRODUCTION}

Spinal cord injury (SCI) is a condition that dramatically changes the life of an individual. Often, a fully functional individual will experience a trauma and then be forever changed, left to live out the remaining years of life with paralysis. Both quadriplegics and paraplegics must learn to alter their entire way of living to accommodate their condition. Annually in the United States, approximately 11,000 people survive an initial trauma and are hospitalized with SCI. Due to the unique nature of SCI, there are varying degrees of paralysis as a result of the impact on multiple systems within the body. Advances in medicine have enabled a number of people living with chronic conditions such as SCI to live increasingly longer lives. As a result, the population of older individuals with SCI is increasing rapidly. In 1992 the National Institute on Disability and Rehabilitation Research (NIDRR) recognized this fact and established an absolute priority to fund a new Rehabilitation Research and Training center (RRTC) that focuses on aging with a spinal cord injury (DeVivo et al., 2010).

Spinal cord injury can be considered a dynamic condition because each person is affected differently. Due to the unique nature of SCI, the case study format is often used to investigate treatment options. Previous studies have been published that describe the effects of resistance training and aerobic exercise in an individual with SCI (Gorgey \& Shephard, 2010; Tawashy et al., 2010). Exercise has been shown to decrease the risk for many of the secondary conditions associated with SCI, including osteoporosis, cardiovascular disease, pressure ulcers, urinary tract infections, diabetes and arthritis. Despite these findings, this population is rarely a target for health promotion effort. The 
present study was designed to explore the effects of a regular yoga routine on the quality of life of a paraplegic individual. The findings of this study could provide those living with paralysis another option on the road to recovery.

According to the National Institutes of Health, as a form of Complementary and Alternative Medicine (CAM), yoga is a holistic approach to health. Originating in India, yoga is a healing system that has been around for approximately 2,000 years. This healing system is comprised of a combination of physical postures known as asanas, breathing techniques known as pranayama and mind focusing exercises known as meditation. These techniques have been used globally to train the mind and strengthen the body. Vallath (2010) found that asanas and pranayama harmonize the physiological system and initiate a "relaxation response" in the neuro-endocrine system. The relaxation response consists of quieter breathing, decreased metabolism, stable blood pressure, reduced muscle tension, lower heart rate and a slow brain wave pattern.

This research study is one of the first studies of its kind to examine the potential relationship between the practice of a yoga routine and the quality of life for an individual that is paralyzed. 


\section{METHODS}

\section{Overview}

This case study was conducted with one participant. For 5 weeks the subject practiced a set yoga routine three times a week with a yoga teacher, receiving private instruction. Each yoga session lasted for one hour. The same yoga routine was taught at each lesson. Interview questions were asked before and after the intervention to document the quality of life for the participant. Each week, prior to the last yoga session of the week, the subject completed a modified SF-36 questionnaire as well as Cohen's Perceived Stress Scale. Perceived pain and perceived stress were the two primary variables monitored in the study.

\section{Subjects}

This was a case study of one 30 year-old paraplegic individual. She has been living with paralysis since age 13 when she was involved in a car accident. She had a C5 level injury (spinal fusion from C5-7), and then fractured her spine at L2, which was left unattended and healed incorrectly, resulting in scoliosis. She has a spinal fusion from T12-L3. The subject is paralyzed below the chest but has normal use of her arms and limited use of her hands. Additionally, she has normal mobility in the head and neck.

\section{Measures}

Perceived pain and perceived stress were the two primary variables investigated in this case study. Characteristics of both measures were depicted in the surveys that the subject was asked to complete each week throughout the study. The perceived stress scale (PSS) by Cohen was used to document stress levels (Cohen et al., 1983). 
"The PSS showed adequate reliability and, as predicted, was correlated with lifeevent scores, depressive and physical symptomatology, utilization of health services, social anxiety, and smoking-reduction maintenance. The PSS is suggested for examining the role of nonspecific appraised stress in the etiology of disease and behavioral disorders and as an outcome measure of experienced levels of stress" (Cohen et al., 1983).

Health-related quality of life (HRQOL) was measured using the 36-item Short Form Health Survey (SF-36). The items in the SF-36 questionnaire are claimed to detect positive as well as negative states of health. Ware and Sherbourne (1992) explained that the SF-36 is a short-form health survey and can be used for multiple purposes. The survey contains only 36 questions and yields and 8-scale profile of functional health and well-being scores. Additionally, it yields a psychometrically-based physical and mental health summary and a preference-based health utility index. The SF-36 is a generic measure that can be used regardless of age, disease or treatment group.

In a comparative study of Iranian veterans and non-veterans with long-standing spinal cord injury, HRQOL was measured using the SF-36 to help determine the physical and mental variables that presumably determined their quality of life. Spinal cord-injured patients experienced poor health-related quality of life (Saadat et al., 2010).

One distinguishing characteristic of a yoga practice is that it is also an awareness practice. As individuals practice yoga they are encouraged to pay attention to their bodies and their breathing, which increases awareness to the way that they function and feel. The surveys completed in the present study provided a qualitative tool to provide 
observational data that documented the subject's experiences as she proceeded through the 5-week yoga program. Both the PSS and modified SF-36 were rated numerically.

\section{Procedures}

Initially, the subject was recruited from an online forum called "Backbones online", which functions as a social networking site for individuals living with paralysis. Once the subject was selected, provided with information about the study, and volunteered, future meeting times were scheduled. Prior to the first session, the subject provided informed, written consent to participate in accordance with the guidelines of the institutional review committee. Interview questions were then addressed by the subject, and the PSS and modified SF-36 were completed.

For a period of 5 weeks, the subject and principal investigator met three times a week to complete the yoga practice intervention. An identical yoga practice schedule/format was conducted at each lesson of the 5-week program. At the end of each week, prior to the final lesson, the subject completed the PSS and SF-36. In addition to the questionnaires, the subject was asked to keep a written log that documented her experiences throughout the study. Each session was accompanied by an assistant who assisted with transferring the subject to the floor in order to perform various exercises. The assistant was also available to help during each lesson in the event an emergency arose.

At the conclusion of the study, the subject again completed the interview questions as well as the PSS and modified SF-36. 


\section{RESULTS}

As a result of this 5-week yoga routine, this subject's perceived stress decreased by $32 \%$; perceived pain and insomnia were also decreased, and there was an increase in overall positive attitude. Additionally, although not measured with a survey, the subject reported having more strength and control over her breathing to help facilitate movement.

A more intimate look at the effects of the yoga practice on the subject's life can be found through the interview questions asked before and after the intervention (Appendix H). Additionally, the subject kept journal notes of observations she made as the study progressed, noting her sleep, bowel and breathing patterns (Appendix F).

The magnitude of improvement in muscular endurance that was attained by the subject during the study was surprising. From week to week the subject clearly became stronger and moved through the yoga routine with ease. The same asanas were repeated each lesson for consistency, but the yoga instructor allowed the subject to hold the final repetition for as long as she felt comfortable. The duration of this specific yoga posture increased from 1-5 breaths at the beginning of the study to 20 breaths by the end of the study, which is comparable to that seen in individuals who are free of injury. Furthermore, the breathing of the subject improved significantly. Initially, a four second inhale/ four second exhale maneuver took considerable concentration, effort and was challenging for the subject. By the fifth week of the yoga training she was able to perform the four- second inhale-exhale procedure easily. She was also able to effectively incorporate the breathing into her other movements and moved with greater ease. 
While there are too many observations to address in this section, one earnest observation comes from the subject's response to an interview statement administered before and after the intervention. Item \#11 was a true-false statement: "I feel strong." Prior to the 5-week yoga training routine the subject answered "false"; at the completion of the study this answer was changed to "true." This change in self-image and perception is typical of some of the changes that were noted in this study.

While most of the data collected in this study was qualitative in nature, scores from the PSS provided quantitative data. To score the PSS, responses are reversed for the four positively stated items and then all scores are summed. The higher overall score indicates high stress levels, the lower the score indicates lower stress levels. Table 1 presents the scores for each item week by week. The largest difference in the scores was from week one to week four. The subject reported a 50\% decrease in perceived stress from week one to week four.

Questions from Perceived Stress Scale:

1. In the last month, how often have you been upset because of something that happened unexpectedly?

2. In the last month, how often have you felt that you were unable to control the important things in your life?

3. In the last month, how often have you felt nervous and "stressed"?

4. In the last month, how often have you felt confident about your ability to handle your personal problems?

5. In the last month, how often have you felt that things were going your way?

6. In the last month, how often have you found that you could not cope with all the things that you had to do?

7. In the last month, how often have you been able to control irritations in your life?

8. In the last month, how often have you felt that you were on top of things?

9. In the last month, how often have you been angered because of things that were outside of your control?

10. In the last month, how often have you felt difficulties were piling up so high that you could not overcome them? 
Optional Responses to Questions 1- 10:

Never $=0$, Almost Never $=1$, Sometimes $=2$, Fairly Often $=3$, Very Often $=4$

Table 1. Perceived Stress Scale Survey Results

\begin{tabular}{ccccccc}
\multicolumn{7}{c}{ Answers by Week } \\
Questions & Start & Wk 1 & Wk 2 & Wk 3 & Wk 4 & Wk 5 \\
1 & 3 & 2 & 2 & 1 & 1 & 1 \\
2 & 2 & 2 & 1 & 1 & 1 & 3 \\
3 & 4 & 3 & 3 & 2 & 1 & 2 \\
4 & 1 & 1 & 1 & 1 & 1 & 1 \\
5 & 1 & 2 & 1 & 1 & 1 & 1 \\
6 & 2 & 1 & 1 & 1 & 1 & 1 \\
7 & 1 & 2 & 1 & 2 & 1 & 1 \\
8 & 1 & 2 & 2 & 2 & 1 & 1 \\
9 & 3 & 3 & 2 & 1 & 1 & 1 \\
10 & 1 & 2 & 2 & 1 & 1 & 1 \\
Totals & $\mathbf{1 9}$ & $\mathbf{2 0}$ & $\mathbf{1 6}$ & $\mathbf{1 3}$ & $\mathbf{1 0}$ & $\mathbf{1 3}$ \\
ghlighted rows indicate the most significant change in score. & & &
\end{tabular}

Modified Sf-36 Questionnaire

1. In general, would you say your health is:

Excellent Very Good Good Fair Poor

2. Compared to one year ago, how would you rate your health in general now?

Much better now than one year ago

Somewhat better now than one year ago

About the same as one year ago

Somewhat worse now than one year ago

Much worse now than one year ago 
3. During the past week, have you had any of the following problems with your work or other regular daily activities as a result of any emotional problems (such as feeling depressed or anxious)?
a. Cut down the amount of time you spent on work or other activities
yes / no
b. Accomplished less than you would like yes / no
c. Didn't do work for other activities as carefully as usual
yes / no

4. How much bodily pain have you had during the past week?
None Very Mild Mild
Moderate Severe
Very Severe

5. During the past week, how much did pain interfere with your normal work (including both work outside the home and housework)?

Not at all A little bit Moderately Quite a bit Extremely

6. These questions are about how you feel and how things have been with you during the past week. For each question, please give the one answer that comes closest to the way you have been feeling. How much of the time during the past week ...

\section{Optional Responses:}

All of the time / Most of the time / Some of the time / A little of the time / None of the time

a. Did you feel full of pep?

b. Have you been a very nervous person?

c. Have you felt so down in the dumps that nothing could cheer you up?

d. Have you felt calm and peaceful?

e. Did you have a lot of energy?

f. Have you felt downhearted and blue?

g. Did you feel worn out?

h. Have you been a happy person?

i. Did you feel tired? 


\section{Table 2. Modified SF-36 Questionnaire Responses by Week}

\begin{tabular}{|c|c|c|c|c|c|c|}
\hline \multirow[t]{2}{*}{ Question } & \multicolumn{6}{|c|}{ Response by Week } \\
\hline & Start & Wk 1 & Wk 2 & Wk 3 & Wk 4 & Wk 5 \\
\hline$\# 1$ & very good & very good & very good & very good & very good & very good \\
\hline$\# 2$ & same as $1 \mathrm{yr}$ & same as $1 \mathrm{yr}$ & same as $1 \mathrm{yr}$ & same as $1 \mathrm{yr}$ & same as $1 \mathrm{yr}$ & same as $1 \mathrm{yr}$ \\
\hline \#3 a. & yes & yes & yes & no & no & yes \\
\hline \#3 b. & no & yes & yes & no & yes & yes \\
\hline \#3 c. & yes & yes & no & no & no & no \\
\hline \#4 & moderate & moderate & mild & mild & moderate & mild \\
\hline \#5 & moderately & moderately & a little bit & a little bit & a little bit & a little bit \\
\hline$\# 6$ a. & $\begin{array}{l}\text { a little of } \\
\text { the time }\end{array}$ & $\begin{array}{l}\text { a little of the } \\
\text { time }\end{array}$ & $\begin{array}{l}\text { a little of } \\
\text { the time }\end{array}$ & $\begin{array}{l}\text { some of the } \\
\text { time }\end{array}$ & $\begin{array}{l}\text { some of the } \\
\text { time }\end{array}$ & $\begin{array}{l}\text { some of the } \\
\text { time }\end{array}$ \\
\hline \#6 b. & $\begin{array}{l}\text { a little of } \\
\text { the time }\end{array}$ & $\begin{array}{l}\text { some of the } \\
\text { time }\end{array}$ & $\begin{array}{l}\text { a little of } \\
\text { the time }\end{array}$ & $\begin{array}{l}\text { some of the } \\
\text { time }\end{array}$ & $\begin{array}{l}\text { a little of } \\
\text { the time }\end{array}$ & $\begin{array}{l}\text { a little of the } \\
\text { time }\end{array}$ \\
\hline \#6 c. & $\begin{array}{l}\text { some of the } \\
\text { time }\end{array}$ & $\begin{array}{l}\text { a little of the } \\
\text { time }\end{array}$ & $\begin{array}{l}\text { none of the } \\
\text { time }\end{array}$ & $\begin{array}{l}\text { none of the } \\
\text { time }\end{array}$ & $\begin{array}{l}\text { none of the } \\
\text { time }\end{array}$ & $\begin{array}{l}\text { none of the } \\
\text { time }\end{array}$ \\
\hline \#6 d. & $\begin{array}{l}\text { a little of } \\
\text { the time }\end{array}$ & $\begin{array}{l}\text { a little of the } \\
\text { time }\end{array}$ & $\begin{array}{l}\text { some of the } \\
\text { time }\end{array}$ & $\begin{array}{l}\text { some of the } \\
\text { time }\end{array}$ & $\begin{array}{l}\text { some of the } \\
\text { time }\end{array}$ & $\begin{array}{l}\text { some of the } \\
\text { time }\end{array}$ \\
\hline \#6 e. & $\begin{array}{l}\text { a little of } \\
\text { the time }\end{array}$ & $\begin{array}{l}\text { a little of the } \\
\text { time }\end{array}$ & $\begin{array}{l}\text { a little of } \\
\text { the time }\end{array}$ & $\begin{array}{l}\text { some of the } \\
\text { time }\end{array}$ & $\begin{array}{l}\text { some of the } \\
\text { time }\end{array}$ & $\begin{array}{l}\text { some of the } \\
\text { time }\end{array}$ \\
\hline \#6 f. & $\begin{array}{l}\text { most of the } \\
\text { time }\end{array}$ & $\begin{array}{l}\text { some of the } \\
\text { time }\end{array}$ & $\begin{array}{l}\text { none of the } \\
\text { time }\end{array}$ & $\begin{array}{l}\text { a little of } \\
\text { the time }\end{array}$ & $\begin{array}{l}\text { a little of } \\
\text { the time }\end{array}$ & $\begin{array}{l}\text { none of the } \\
\text { time }\end{array}$ \\
\hline \#6 g. & $\begin{array}{l}\text { most of the } \\
\text { time }\end{array}$ & $\begin{array}{l}\text { most of the } \\
\text { time }\end{array}$ & $\begin{array}{l}\text { some of the } \\
\text { time }\end{array}$ & $\begin{array}{l}\text { some of the } \\
\text { time }\end{array}$ & $\begin{array}{l}\text { some of the } \\
\text { time }\end{array}$ & $\begin{array}{l}\text { a little of the } \\
\text { time }\end{array}$ \\
\hline \#6 h. & $\begin{array}{l}\text { a little of } \\
\text { the time }\end{array}$ & $\begin{array}{l}\text { some of the } \\
\text { time }\end{array}$ & $\begin{array}{l}\text { some of the } \\
\text { time }\end{array}$ & $\begin{array}{l}\text { some of the } \\
\text { time }\end{array}$ & $\begin{array}{l}\text { some of the } \\
\text { time }\end{array}$ & $\begin{array}{l}\text { most of the } \\
\text { time }\end{array}$ \\
\hline \#6 i. & $\begin{array}{l}\text { most of the } \\
\text { time }\end{array}$ & $\begin{array}{l}\text { most of the } \\
\text { time }\end{array}$ & $\begin{array}{l}\text { some of the } \\
\text { time }\end{array}$ & $\begin{array}{l}\text { some of the } \\
\text { time }\end{array}$ & $\begin{array}{l}\text { some of the } \\
\text { time }\end{array}$ & $\begin{array}{l}\text { some of the } \\
\text { time }\end{array}$ \\
\hline
\end{tabular}


While there are many factors that contribute to HRQOL, depression is often a psychological state that is measured. Figure 1 shows that the subject's mental state of feeling downhearted and blue was reduced over the course of the study. In the first week she identified feeling downhearted "most of the time"; this was reduced to "none of the time" at the end of the study.

Figure 1. Subject response to Question $6 F$ from SF-36 survey.

\section{Response to Question 6F. Have you felt downhearted and blue?}

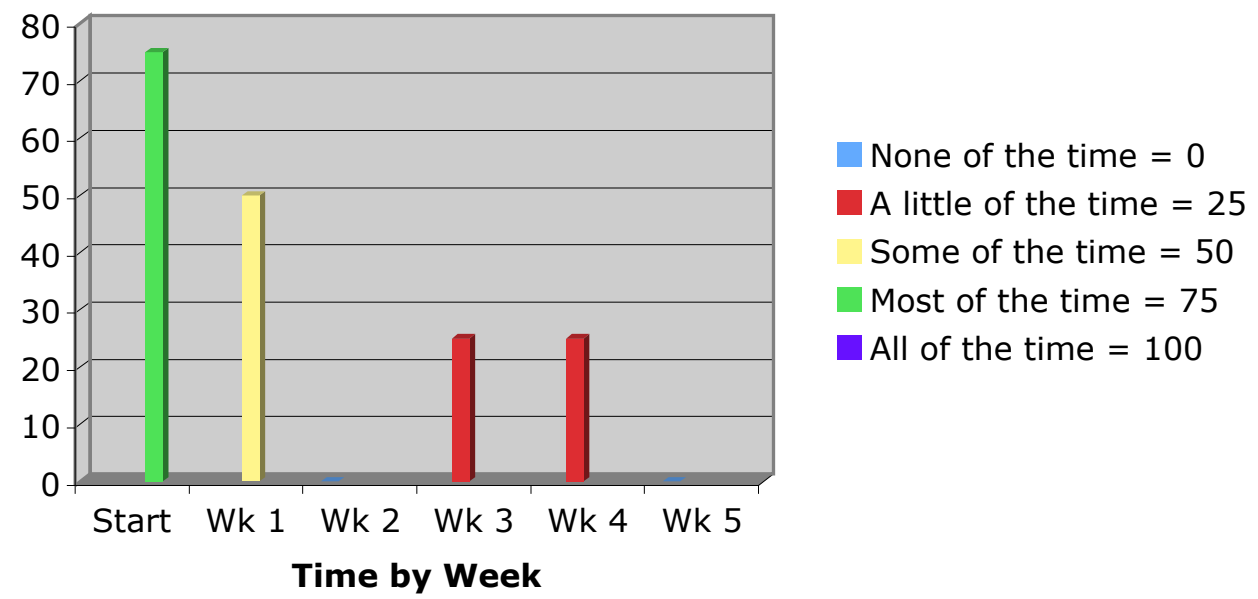

Another observation worth mentioning is the response to question $6 \mathrm{H}$ from the SF-36. Question 6H asks, "Have you been a happy person?” Prior to starting the yoga intervention the subject responded that she was happy "a little of the time", but by the end of the five-week study, her response changed to "most of the time" (Table 2.)

The purpose of this study was to describe the effect of a regular yoga routine on the quality of life of an individual living with paralysis. While a variety of measurements can be used when discussing HRQL, perceived pain and stress were chosen as dependent 
variables. While conducting background research it became apparent that both pain and stress are concerns for individuals living with paralysis, and may be positively affected by the practice of yoga. Pang et al. (2009) reported that depressive behaviors and pain interference are significantly associated with disease management self-efficacy in individuals with SCI.

This study revealed that a yoga routine can be a viable form of exercise for an individual with SCI and that by participating in a yoga routine 3 times per week, participants may improve their quality of life by reducing pain and stress. The subject was able to complete the yoga routines without any negative effects or injury. The subject exhibited several signs of increased physical functioning (e.g., ease in transfer, ease in movement, sustained strength exercise and deeper breathing). These changes indicate that there were some positive muscular adaptations that presumably resulted from the yoga routine.

\section{Limitations}

The findings in this case study have a number of limitations that must be acknowledged and should be considered in future research efforts. First, the duration of the intervention was a major limitation in this study. The yoga intervention was limited to 5-weeks because of the availability of both the subject and principal investigator. Ideally, a longer-term study would allow researchers to follow a subject over a span of years to document both the short-term and long-term effects of a regular yoga practice.

This study is also limited by a small sample size. It would be beneficial if an experimental study could be conducted with an appropriate control group. Alternatively, 
multiple case studies with the same yoga routine would improve the extent to which the results of the current study can be generalized to others with SCI. However, each case study would require multiple instructors or assistants due to the challenges related to guiding each individual through the yoga routine. Because of the paralysis, hands-on assistance is required throughout the entire yoga routine. Despite the inability to generalize the results of this study, it would be beneficial to replicate this study to determine whether similar results would be experienced by other SCI individuals who perform yoga training.

Finally, in addition to qualitative self-report measures used in this study, it would be useful to include physiological measures such as blood pressure, heart rate, and oxygen uptake. For example, salivary cortisol samples could provide biological data related to stress. Such physiological measures would improve the validity of the study and could increase ability to investigate potential mechanisms. 


\section{REFERENCES}

Cohen, S., Kamarck, T., \& Mermelstein, R. (1983). A global measure of perceived stress. Journal of Health and Social Behavior, 24. Retrieved from http://www.jstor.org/pss/2136404

DeVivo, M., Shewchuk, R., Stover, S., Black, K., \& Go, B. (1992). A cross-sectional study of the relationship between age and current health status for the persons with spinal cord injuries. Paraplegia, 30, 820-827.

Gorgey, A. \& Shepherd, C. (2010). Skeletal muscle hypertrophy and decreased intramuscular fat after unilateral resistance training in spinal cord injury: Case report. The Journal of Spinal Cord Medicine, 33. Retrieved from http://www.ncbi.nlm.nih.gov/pmc/articles/PMC2853337/?tool=pubmed

Kehn, M. \& Kroll, T. (2009). Staying physically active after spinal cord injury: a qualitative exploration of barriers and facilitators to exercise participation. $B M C$ Public Health, 9, doi: 10.1186/1471-2458-9-168

Pang, M., Eng, J., Lin, K., Tang, P., Hung, C., \& Wang, Y. (2009) Association of depression and pain interference with disease-manegement self-efficacy in community-dwelling individuals with spinal cord injury. Journal of Rehabilitation Medicine, 41, 1068-1073.doi: 10.2340/16501977-0455

Paralysis. (n.d.). In Oxford Dictionary online. Retrieved from $\mathrm{http}: / /$ oxforddictionaries.com/definition/paralysis?region=us

Saadat, S., Javadi, M., Divshali, B., Tavakoli, A., Ghodsi, M., Montazeri, A., \& RahimiMovaghar, V. (2010). Health-related quality of life among individuals with longstanding spinal cord injury: A comparative study of veterans and non-veterans. BMC Public Health, 10, doi: 10.1186/1471-2458-10-6 
Tawashy, A., Eng, J., Krassioukov, A., Miller, W., \& Sproule, S. (2010). Aerobic exercise during early rehabilitation for cervical spinal cord injury. Physical Therapy, 90, 427-437.doi: 10.2522/ptj.20090023

Vallath, N. (2010). Perspectives on yoga inputs in the management of chronic pain. Indian Journal of Palliative Care, 16, 1-7. doi:10.4103/0973-1075.63127

Ware, J. \& Sherbourne, C. (1992). The MOS 36-item short-form health survey (SF-36): I. Conceptual framework and item selection. Medical Care, 30, 473-483. Retrieved from http://www.jstor.org/stable/3765916

Whiteneck, G., Gassaway, J., Dijkers, M., \& Jha, A. (2009). New approach to study the contents and outcomes of spinal cord injury rehabilitation: The SCIRehab Project. The Journal of Spinal Cord Medicine, 32, 251-259. Retrieved from http://www.ncbi.nlm.nih.gov/pmc/articles/PMC2718827

Woodyard, C. (2011). Exploring the therapeutic effects of yoga and its ability to increase quality of life. International Journal of Yoga, 4, 49-54. 


\section{APPENDIX A}

\section{Literature Review}

This review examines previous research in four focus areas: yoga therapy, instruments used to measure health-related quality of life (HRQOL), spinal cord injury (SCI) case studies, and respiratory complications associated with SCI. The goal of this literature review is to clarify the link between this study and previous research in these areas and to demonstrate where this study fits in with the future of SCI treatment. Additionally, it provides a context for the interpretation of the results of this study.

\section{Yoga Therapy Research}

Although it is thought that yoga has been around for 2,000 years, Yoga Therapy research is a relatively new and emerging field. The teachings of yoga and the industry related to its practice have evolved since the 1970's — after a pilgrimage of Gurus first came to the United States. The role that yoga has as a therapeutic modality is described by Woodyard (2011): "Yoga engages the student in the healing process; by playing an active role in their journey toward health, the healing comes from within, instead of from an outside source and a greater sense of autonomy is achieved."

Matthew Sanford, author of the book Waking: A memoir of Trauma and Transcendence (2006), describes the role that yoga has played in his life as he has healed and learned to live with paralysis. Sanford is now a yoga teacher and believes that "We define sensation too narrowly, in part because we defer too much to the limiting opinions 
of healthcare experts rather than cultivating and listening to the voice from within. Yoga helps us hear and reestablish the link to the inner voice" (Sanford, 2007). As described by Sanford and other paraplegics, participation in a yoga routine may produce life-enhancing benefits for individuals with SCI such as improved bowel and bladder control, improved efficiency of transfers, and enhanced sexual functioning.

Health related quality of life is a multifactorial construct that is used to describe one's daily functioning. Chronic pain is one element of HRQL that plays a significant role that is particularly important to individuals living with SCI. In this thesis, pain was a primary measure being observed in the subject. The Indian Journal of Palliative Care published a comprehensive paper discussing the history of yoga and how yoga can be used in the management of chronic pain. For example, Vallath (2010) noted that asanas and pranayama work to harmonize the physiological system and initiate a 'relaxation response' in the neuro endocrinal system. This relaxation response consists of decreased metabolism, quieter breathing, stable blood pressure, reduced muscle tension, lower heart rate and slow brain wave pattern. The asanas bring steadiness, health and lightness of the body and optimize tissue functioning. Additionally, asanas are useful adjuncts in the maintenance phase for reconditioning the body, realignment of skeleton and for correction of postures.

In addition to asana practice, meditation was also mentioned, meditation and pranayama, along with relaxing asanas, can help individuals deal with the emotional aspects of chronic pain, reduce anxiety and depression effectively and improve perceived quality of life (Vallath, 2010). Utilizing cortisol levels as a marker of stress, Curtis et al. 
(2011) studied an eight-week yoga intervention to examine whether a yoga practice would positively affect the cortisol levels in women with fibromyalgia. Twenty-two participants were recruited to participate in a 75-minute yoga class twice weekly for 8 weeks. Questionnaires — including the Perceived Stress Scale (PSS) — were completed by participants. Salivary cortisol samples were collected three times each day for two days, before and after the intervention. They concluded that a yoga intervention may reduce pain and catastrophizing, increase acceptance and mindfulness, and alter total cortisol levels in women with fibromyalgia. The mind-body connection of pain and stress can decrease function and increase anxiety and depression if untreated. "The physiology is in a state of persistent stress with the hypothalamic-pituitary-adrenal axis and the sympathetic system, in a state of hyper arousal." (Vallath, 2010).

Yoga Therapy is often placed under the umbrella of Complementary and Alternative Medicine (CAM). According to Centers for Disease Control (CDC) reports, \$36-\$47 billion was spent on CAM therapies in 1997, and about half of that money was spent out-of-pocket. Those figures surpass the amount paid out-of-pocket in the United States for all hospitalizations in 1997 (London, 2007). While CAM is getting an increasing amount of attention, a number of researchers in academia are working steadfast to augment yoga therapy research.

Hybrid researchers and yogis like Sat Bir Singh Khalsa are working to bridge the gap between the mystical and academia. In the International Journal of Yoga Therapy, Khalsa blatantly asks the readers: "Why do yoga research: Who Cares and What Good Is it?" (Khalsa, 2007). In the article Khalsa, who works at Harvard, explains that $7.5 \%$ of 
the population currently practices yoga and that it is critical to evaluate yoga's use for both safety and efficacy. Khalsa (2007) articulates that, carefully designed and executed research studies that convincingly validate yoga's physical and psychological benefits will be required before yoga practices can be broadly applied to a large number of populations including: children, the elderly, and patients in institutions such as hospitals, schools and offices.

Dr. London, a psychiatrist practicing at the New York University Medical Center observed this in his patients "Over and again, I heard from people that yoga results in a feeling of peace and tranquility, and that with these newfound feelings, a sense of self and calmness allows the practitioner to be better able to meet life on life's terms" (London, 2007). London (2007) found breathing and asana routine activate the parasympathetic nervous system and reduce the emotional chaos of cognitive dissonance. Furthermore, when the parasympatheic activation occurs, a decrease in cortisol levels signifies the reduction of stress.

Yoga research is relatively new in the United States but a number of research centers dedicated specifically to yoga have been operational in India for a number of years. In a recent 2012 study conducted in Bengaluru, India, researchers used a 7-day intensive yoga program for patients with chronic low back pain (CLBP). The yoga program consisted of specific asanas and pranayamas for back pain, meditation, yogic counseling, and lectures on yoga philosophy. The control group program included physical therapy exercises for back pain, and matching counseling and education sessions. The yoga group experienced a $49 \%$ decrease in pain compared to the control 
group that experienced a $17.5 \%$ decrease (Tekur et al., 2012). This study concluded a seven-day intensive residential yoga program reduces pain, anxiety, and depression, and improves spinal mobility in patients with CLBP more effectively than physiotherapy exercises (Tekur et al., 2012). Traditionally in the United States, physical therapy serves as the main tool for rehabilitation but this study provides one example of how physical therapy and yoga can provide very different results.

\section{Measures}

While conducting background research, the issue of chronic pain was determined to be an everyday focus for individuals living with SCI. Based on that feedback, the measures for this study were determined. Perceived stress and perceived pain were measured in this 5-week study using a modified SF-36 form and the Perceived Stress Scale by Cohen et al. (1983).

The Medical Outcomes Study 36-Item Short-Form Health Survey (SF-36) has been used in a number of studies related to SCI (Saadat et al., 2010; Middleton et al., 2007; Kreuter et al., 2005). Because not all of the questions in the SF-36 were relevant to the subject in this study, the SF-36 was modified. For instance, questions related to walking, bending and stooping were removed from the survey. As stated in the Elfstrom et al. (2005) study, for individuals with traumatic spinal cord lesion (SCL), extended life spans and the need for life-long follow-up make it important to expand the outcome parameters of medical care and health services to include HRQL measures. The Elfstrom study sent questionnaires related to HRQL to 256 persons with traumatically acquired spinal cord lesions. Study participants were chosen if they had been a patient at the 
Gothenburg Spinal Injuries Unit between the years 1982 and 1998. To measure HRQL, the SF-36, The Spinal Cord Injury Quality of Life Questionnaire, and standardized global questionnaire of overall quality of life were used.

In a study by Middleton et al. (2007), the objective was to study the interaction between quality of life in people with SCI and expectations of daily living (self-efficacy) and pain. Two questionnaires were sent by mail for the 106 participants to complete at home regarding their post-rehabilitation stage. Participants received no treatments as part of the study. The study found that those living with SCI had a lower quality of life compared to the able bodied general population (Middleton, 2007). Middleton et al. also concluded that rehabilitation strategies may need to concentrate on improving QOL by targeting low self-efficacy. The SF-36 was used to explore the relationship between quality of life and self-efficacy in persons with spinal cord injuries. In addition to the SF36, the Moorong Self-Efficacy scale was used.

The SF-36 has not only been used in the United States as a measure for HRQL but also globally in Iran, Australia and Sweden. Kreuter et al., (2005) compared individuals from Australia and Sweden with spinal cord lesions. Two groups consisting of 89 Australian citizens and 71 Swedish citizens with SCL were surveyed. The groups were matched according to sex, age, time since injury and level of injury. The SF-36 and the Spinal Cord Injuries Quality of Life-23-item questionnaire were used to cover essential generic and specific measures of health and quality of life. The goal of the study was to demonstrate the value of common general HRQL instruments, readily available for crosscultural comparisons in persons with SCL. Interestingly, this study concluded that 
individuals with SCL are the logical experts in maintenance of personal roles, social interaction and emotional well-being.

Motor vehicle accidents, falls, acts of violence including warfare, sports activities such as diving into shallow water and diseases are the main causes of SCI (Jang et al., 2011). During the 1980-1988 Iran-Iraq war, the human cost to Iran included more than 200,000 lives lost and more than 400,000 persons injured, of whom 2,012 were veterans with spinal cord injury (Saadat, 2010). Saadat (2010) conducted a study in Tehran, Iran using the SF-36 to assess quality of life in male spinal cord injured veterans to compare HRQL between veterans and non-veterans with SCI. This was a cross-sectional study. Thirty-nine male veterans and 63 non-veteran males with SCI were included in the study. To determine the variables affecting physical and mental health-related quality of life among the patients, regression analyses were applied (Saadat et al., 2010). The SF-36 questionnaire comprises measures of physical functioning, bodily pain, role limitation due to physical problems, health perceptions, social functioning and mental health. While the focus is often on the physical adjustment of living with paralysis, the mental health component of living with a chronic condition is also important. "Pain is highly related to other psychosocial variables, such as depression and psychological stress in people" (Pang et al., 2009).

The other instrument used in this study was the PSS. The Perceived Stress Scale (PSS) was designed to improve research of value of clinical judgments in the assessment of psychopathology (Spitzer et al., 1980). "The PSS is suggested for examining the role of nonspecific appraised stress in the etiology of disease and behavioral disorders and as 
an outcome measure of experienced levels of stress" (Cohen et al., 1983). Based on existing research (Shannahoff-Khalsa et al., 1999; Brisbon \& Lowery, 2011; Kovacic \& Kovacic, 2011) it appears that the PSS is often used as a measure in studies examining the use of yoga in the healing process. Brisbon and Lowery, (2011) compared mindfulness and levels of stress between beginner and advanced practitioners of Hatha yoga. Advanced practitioners were characterized as having more than 5 years experience in Hatha yoga and beginners were defined as having practiced less than 5 years. Advanced practitioners had significantly higher mindfulness scores and lower stress levels than the beginner practitioners. Cohen's PSS survey was used to measure these changes prior to the Hatha yoga class.

Kovacic and Kovacic (2011) conducted a study in Slovenia, which used the PSS in conjunction with other measures to examine the impact of relaxation training on perceived stress after breast cancer surgery. Researchers used this pilot study to gather information about the immediate and short-term effects of relaxation training according to a registered program titled "Yoga In Daily Life" (YIDL). The study found patients who received relaxation training in the form of YIDL reported feeling significantly less distressed during hospitalization and after discharge-period than did the controls that did not receive the relaxation training (Kovacic \& Kovacic, 2011).

Continuing to explore the mind-body connection, researchers used Kundalini yoga techniques on eleven adults with obsessive-compulsive disorder (OCD) (Shannahoff-Khalsa, 1999). A second group of ten adults with OCD were offered the Relaxation Response plus Mindfulness Meditation technique. The PSS was used to 
measure the effects of yogic meditation techniques on this psychological disorder. The Kundalini yoga group significantly improved on all six scales used for measurement, including the PSS, while the second group did not experience any improvement. It was concluded that Kundalini yoga techniques could be effective in the treatment of OCD.

A large body of research suggests that movement can facilitate a positive psychological state, which affirms the mind-body connection discussed in yoga research (Haisma et al., 2007; Mishra et al., 2009). The West et al. (2005) study conducted at Reed College examined the effects of both Hatha yoga and African dance on perceived stress, affect and salivary cortisol. The PSS was once again used to track perceived stress levels. Sixty-nine healthy college students participated in one of three 90-min classes: African dance, Hatha yoga or a biology lecture (the control condition). It was concluded that both African dance and Hatha yoga reduced perceived stress and negative affect. All of the studies described in this section of the review have used the Perceived Stress Scale to examine and measure the psychological effects of yoga related interventions such as meditation, hatha yoga practice and relaxation training.

\section{Case studies for Individuals living with SCI}

Often, the case study format is used when studying individuals with SCI because each case varies so greatly, depending on the site of trauma and ability level of the individual with SCI. A number of studies examining factors such as bladder control, skeletal muscle hypertrophy, and the affects of aerobic exercise during rehabilitation have been conducted (Tawashy et al., 2009; Gorgey, 2010; Kennelly et al., 2010). SCI is a debilitating condition that can result in devastating effects of both psychological and 
physical functioning altering independence of the injured individual (Pang et al., 2009).

Previously in the literature review, the importance of the mind-body relationship has been described in relation to individuals living with SCI. Tawashy and colleagues, (2009) found conditions such as pain, fatigue and depression have been linked to physical inactivity in both the general population and adults with chronic conditions.

In one study with a design similar to this thesis study, Tawashy et al. (2009) observed the effects of aerobic exercise during early rehabilitation for cervical spine injury. This was a case study of a 22-year-old male who had sustained a complete C5 SCI during a swimming accident. The exercise program consisted of 18 sessions over a 2month period. "The subject exhibited several signs of improved exercise tolerance and wheelchair mobility during the 2-month program" (Tawashy et al., 2010).

In addition to using aerobic training and yoga training in rehabilitation of individuals with SCI, a study by Gorgey (2010) examined the effects of neuromuscular electrical stimulation resistance training (NMES-RT). The training was directed to individual muscle groups and adipose tissue of the right thigh after stimulation of the knee extensor muscle. This was a case study of one 22 year-old male with SCI resulting from a motorcycle accident 5 years prior to participation in the study. The subject underwent training twice a week for 12 weeks. At the end of the 12 weeks, the participant was able to lift $17 \mathrm{lbs}$ during full knee extension. Intramuscular fat had decreased by more than $50 \%$ and subcutaneous fat increased by $24 \%$ (Gorgey, 2010).

Kennelly et al. (2010) used electrical stimulation of the urethra to evoke bladder contractions in a woman with spinal cord injury. "Electrical stimulation of pudendal 
urethral afferents generates coordinated micturition in animals and bladder contractions in men after spinal cord injury (SCI), but there is no evidence of an analogous excitatory urethra-spinal-bladder reflex in women" (Kennelly et al., 2010). For this study, a 38-yearold woman with a C6 SCI who managed her bladder with clean intermittent catheterization and oxybutynin, demonstrated neurogenic detrusor overactivity on urodynamics (Kennelly et al., 2010). The finding of this case study were that electrical stimulation via urethral electrodes evoked bladder contractions that were dependent on bladder volume and the intensity of stimulation. These case studies provide an in-depth look at possible rehabilitation therapies that can be used with individuals living with SCI, and provide additional insight for future research.

\section{$\underline{\text { Respiratory complications associated with SCI }}$}

One essential component of the yoga practice in this thesis study was the pranayama practice. Breathing is typically used in a regular yoga practice to bring the mind and body into the same plane. In this study, breathing served as a facilitator of the mind-body connection but also as a strengthening tool to improve respiratory function. Although lung capacity was not measured in this study, results of pranayama practice were noted by the subject and principal investigator. A number of previous studies have supported the idea that respiratory complications are the most important cause of morbidity and mortality in individuals with SCI (Brown et al., 2006; Tollefsen \& Fondenes, 2012; Litchke et al., 2008).

Tollefsen and Fondenes (2012) suggested that patients with spinal cord injury require a multi-disciplinary approach when searching out treatment. "In the acute phase 
following a spinal cord injury, up to $80 \%$ of patients are affected by respiratory complications" (Tollefsen and Fondenes, 2012). The Tollefsen article is based on a nonsystematic search in PubMed and the authors' personal clinical experience in treatment and follow-up of respiratory complications in patients with spinal cord injury. Long-term follow-up revealed that respiratory complications were the most frequent cause of death. Brown et al. (2006) similarly stated, respiratory dysfunction is a major cause of morbidity and mortality in SCI, which causes reduction in lung and chest wall compliance, impairment of respiratory muscles, reduced vital capacity, ineffective cough, and excess oxygen cost of breathing due to distortion of the respiratory system. The Brown article was essentially a review of respiratory care for individuals with SCI and noted that the most common complications were pneumonia and respiratory failure. Respiratory complications are also strongly correlated with length of a patient's stay in hospital.

While the specific effects of yogic breathing known as pranayama have yet to be studied on individuals with SCI, one intervention that appears to be the closest to pranayama is respiratory muscle training. "In the able-bodied, it has been demonstrated that, like other skeletal muscles, the muscles of ventilation can be trained for both strength and endurance" (Brown et al., 2006). Similar to other muscle groups in the body, vigorous and forceful efforts are required to produce a significant effect. Unfortunately, there is very little research on the use of respiratory muscle training. Most respiratory rehabilitation efforts associated with SCI employ machines such as ventilators and respiratory resistance training, which regulates the amount of airflow; this reduces the amount of oxygen so that participants must work harder and breathe deeper. These 
breathing devices can create situations similar to an aerobic workout or breathing at a higher elevation.

Litchke et al. (2008) compared respiratory function in able-bodied individuals and individuals with SCI. "When tested in a seated position, persons with SCI at C5-C8 had $21 \%$ lower total lung capacity, $44 \%$ lower vitality capacity, and $27 \%$ higher residual lung volume compared to able-bodied individuals" (Litchke et al., 2008). Based on these findings it is concluded that the reduction in respiratory function can significantly limit exercise capacity for persons with SCI. 


\section{APPENDIX B}

\section{References for Literature Review}

Barker, R., Kendall, M., Amsters, D., Pershouse, K., Haines, T., \& Kuipers, P. (2009). The relationship between quality of life and disability across the lifespan for people with spinal cord injury. Spinal Cord, February, 149-155.

Brisbon, N., \& Lowery, G. (2011). Mindfulness and levels of stress: a comparison of beginner and advanced Hatha Yoga practitioners. Journal of Religion and Health, December, 931-941.

Brazier, J., Harper, R., Jones, N., O’Cathain, A., Thomas, K., Usherwood, T., \& Westlake, L. (1992). Validating the SF-36 health survey questionnaire: new outcome measures for primary care. BMJ, Volume 305, 160-164.

Bowden, D., Gaundry, C., Seung Chan, A., \& Gruzelier, J. (2012). A comparative randomized controlled trial of the effects of brain wave vibration training, Iyengar yoga, and mindfulness on mood, well-being, and salivary cortisol. EvidenceBased Complementary and Alternative Medicine, Volume 2012, Article ID 234713. doi:10.1155/2012/234713.

Brown, R., DiMarco, A., Hoit, J., \& Garshick, E. (2006). Respiratory dysfunction and management in spinal cord injury. Respiratory Care, Volume 51, 853-870.

Cohen, S., Kamarck, T., \& Mermelstein, R. (1983). A global measure of perceived stress. Journal of Health and Social Behavior, 24. Retrieved from http://www.jstor.org/pss/2136404

Curtis, K., Osadchuk, A., \& Katz, J. (2011). An eight-week yoga intervention is associated with improvements in pain, psychological functioning and mindfulness, and changes in cortisol levels in women with fibromyalgia. Journal of Pain Research, 189-201. 
DeVivo, M., Shewchuk, R., Stover, S., Black, K., \& Go, B. (1992). A cross-sectional study of the relationship between age and current health status for the persons with spinal cord injuries. Paraplegia, 30, 820-827.

Elfstrom, M., Ryden, A., Kreuter, M., Taft, C., \& Sullivan, M. (2005). Relations between coping strategies and health-related quality of life in patients with spinal cord lesion. Journal of Rehabilitation Medicine, January, 9-16.

Gorgey, A., \& Shepherd, C. (2010). Skeletal muscle hypertrophy and decreased intramuscular fat after unilateral resistance training and spinal cord injury: Case report. Journal of Spinal Cord Medicine, 33, 90-95.

Haisma, J., Bussman, J., \& Stam, H. (2007). Physical fitness in people with a spinal cord injury: the association with complications and duration of rehabilitation. Clinical Rehabilitation, 21, 932-940.doi: 10.1177/0269215507079134

Jang, H., Park, J. \& Shin, H. (2011). Length of hospital stays in patients with spinal cord injury. Annals of Rehabilitation Medicine, 35, 798-806. doi: 10.5535/arm.2011.35.6.798

Kennelly, M., Arena, K., Shaffer, N., Bennett, M., Grill, W., Grill, J., \& Boggs, J. (2010). Electrical stimulation of the urethra evokes bladder contractions in a woman with spinal cord injury. The Journal of Spinal Cord Medicine, 33, 261-265.

Khalsa, S. (2007). Why do yoga research: who cares and what good is it? International Journal of Yoga Therapy, 19-20. Retrieved from http://www.iayt.org/research_Vx2/summaries.aspx?AutoID $=\& U S t a t u s=\&$ Profile Number $=\& \mathrm{LS}=\& \mathrm{AM}=\& \mathrm{Ds}=\& \mathrm{CI}=\& \mathrm{AT}=\&$ Return $=$ 
Kovacic, T., \& Kovacic, M. (2011). Impact of relaxation training according to Yoga in Daily Life system on perceived stress after breast cancer surgery. Integrative Cancer Therapies, 10, 16-26.

Kreuter, M., Siosteen, A., Erkholm, B., Bystrom, U., \& Brown, D. (2005). Health and quality of life in persons with spinal cord lesion in Australia and Sweden. Spinal Cord, February, 123-129.

Litchke, L., Russian, C., Lloyd, L., Schmidt, E., Price, L., \& Walker, J. (2008). Effects of respiratory resistance training with a concurrent flow device on wheelchair athletes. Journal of Spinal Cord Medicine, 31, 65-71.

London, R. (2007). Yoga: a beneficial integrative therapy. Clinical Psychiatry News, 20. Retrieved from http://galenet.galegroup.com/servlet/HWRC/hits?r=d7origsearch=false\&o=\&buck et $=$ per

Middleton, J., Tran, Y., \& Craig, A. (2007). Relationship between quality of life and selfefficacy in persons with spinal cord injuries. Archives of physical medicine and rehabilitation, December, 1643-1648.

Mishra, S., Aziz, N., Scherer, R., Baquet C., Berlanstein, D., \& Geigle, P. (2009). Exercise interventions on health related quality of life for cancer survivors (Protocol). The Cochrane Collaboration. doi: 10.1002/14651858.CD007566

Pang, M., Eng, J., Lin, K., Tang, P., Hung, C., \& Wang, Y. (2009) Association of depression and pain interference with disease-manegement self-efficacy in community-dwelling individuals with spinal cord injury. Journal of Rehabilitation Medicine, 1068-1073.doi: 10.2340/16501977-0455

Saadat, S., Javadi, M., Divshali, B., Tavakoli, A., Ghodsi, M., Montazeri, A., \& RahimiMovaghar, V. (2010). Health-related quality of life among individuals with longstanding spinal cord injury: a comparative study of veterans and non-veterans. BMC Public Health, doi: 10.1186/1471-2458-10-6 
Sanford, M. (2006). Waking: A memoir of Trauma and Transcendence.

Sanford, M. (2007). Yoga and SCI: when adapted to the needs of people with physical disabilities-and with appropriate assistance-yoga can be a valuable healing tool. Parplegia News, 61. 24-30.

Shannahoff-Khalsa, D., Ray, L., Levine, S., Gallen, C., Schwartz, B., \& Sidorowich, J. (1999). Randomized controlled trial of yogic meditation techniques for patients with obsessive-compulsive disorder. CNS Spectrum, December,34-47.

Spitzer, R., Endicott, J., Cohen, J., \& Nee, J. (1980). The Psychiatric status schedule for epidemiological research. Methodological considerations. Archives of general psychiatry, October, 1193-1197.

Tawashy, A., Eng, J., Lin, KH., Tang, PF., \& Hung, C. (2009). Physical activity is related to lower levels of pain, fatigue, and depression in individuals with spinal cord injury: A correlational study. Spinal Cord, April, 301-306. doi: $10.1038 / \mathrm{sc} .2008 .120$

Tekur, R., Nagarathna, A., Chametcha, S., Hankey, A., \& Nagendra, H.R. (2012). A comprehensive yoga program improves pain, anxiety and depression in chronic low back pain patients more than exercise: An RCTP. Complementary Therapies in Medicine, 20, 107-118.

Tollefsen, E., \& Fondenes, O. (2012). Respiratory complications associated with spinal cord injury. Tidsskr Nor Legeforen, 132, 1111-1114. doi: 10.4045/tidsskr.10.0922

Vallath, N. (2010). Perspectives on yoga inputs in the management of chronic pain. Indian Journal of Palliative Care, 16, 1-7. doi:10.4103/0973-1075.63127 
West, J., Otte, C., Geher, K., Johnson, J., \& Mohr, D. (2004). Effects of Hatha yoga and African dance on perceived stress, affect and salivary cortisol. Annals of behavioral medicine, October, 114-118.

Woodyard, C. (2011). Exploring the therapeutic effects of yoga and its ability to increase quality of life. International Journal of Yoga, 4. 49-54. 


\section{APPENDIX C}

\section{Participant Information and Informed Consent}

You are invited to participate in an exercise science study about the use of yoga therapy on a paraplegic individual. This study is called "Effects of Yoga Therapy on a Paraplegic Individual's Quality of Life". This is a thesis project conducted by Allison Renee Purdy in partial fulfillment of requirements for a Master's Degree in Health Studies (Portland State University, School of Community Health; Advisor- Gary Brodowicz, Ph.D.).

The purpose of this study is to investigate the relationship between yoga practice and the quality of life in an individual living with paralysis.

If you agree to volunteer as a subject for this study, you will be asked to participate in 18 yoga lessons (three one-hour sessions a week for six weeks). These lessons will be private and will be tailored to your individual needs, with an identical session protocol for all eighteen lessons. In each yoga session, breathing, meditation and movement instruction will be included. As a volunteer, you may withdraw from the study at any time.

Methods: The participant will engage in fifteen, one-hour yoga sessions. The participant will complete surveys related to perceived stress and perceived pain periodically throughout the study. All surveys will first be administered prior to the first yoga session, again at the end of each week, and at the conclusion of the study. The study will take place at YoYoYogi yoga studio, 1306 NW Hoyt Street, Suite 101,Portland, OR, 97209. The studio is handicapped accessible.

Benefits: The participant will receive fifteen private yoga lessons free of charge and will learn breathing, mediation and movement techniques from a certified yoga professional.

Risks and Safeguards: a trained professional will monitor the participant for the entire yoga lesson. The principal investigator and yoga instructor (Allison Purdy) is a certified Yoga teacher and is also CPR certified. In addition to Allison Purdy, another certified yoga teacher, Terri Cole, will be in the studio to offer support during the transfers from wheelchair to the floor and from the floor back up to the wheelchair. Terri is the studio owner and will also be available to contact help if an emergency were to arise.

Any information that is obtained in connection with this study and that can be linked to you or identify you will be kept confidential. Original data, signed forms and surveys will be kept only by the principal investigator, Allison Renee Purdy, and will be preserved for a minimum of three years after the completion of research. The study participant will receive copies of their own-signed informed consent. There are limits to confidentiality 
of information; for example, the state of Oregon requires that all suspected or confirmed cases of child and elder abuse must be reported to authorities.

Your signature below indicates that you have read and understand the above information and agree to take part in this study. Please understand that you may withdraw your consent at any time without penalty, and that, by signing, you are not waiving any legal claims, rights or remedies. The researcher will provide you with a copy of this form for your own records.

Signature Date

Printed Name

Contact Information:

Allison Renee Purdy, Principal Investigator

Allison.Purdy@gmail.com

503.936 .2318

Gary Brodowicz, Ph.D., Advisor

Portland State University, School of Community Health

brodowiczg@pdx.edu

503.725 .5119

Human Subjects Research Review Committee

Office of Research and Sponsored Projects

600 Unitus Building

Portland State University

503.725 .4288

1.877 .480 .4400 


\title{
APPENDIX D \\ Yoga Routine for a Paraplegic Woman
}

\author{
1-Hour Practice
}

The participant will be transferred to the floor from her wheelchair. The yoga teacher and assistant yoga teacher will perform the transfer onto a padded area of the floor at YoYoYogi, yoga studio. The subject will be assisted and observed throughout the entire practice by the yoga teacher.

Seated

1. Seated Breathing

-10 Ujjayi breaths

-Breathe in and out through the nose.

Inhale for a count of 4 , exhale for a count of 4 .

-The subject will be seated on floor supported by bolster pillow behind the low back.

-Ujjayi breathing helps to increase lung capacity, strengthen the rib cage and improve quality of breath.

2. Seated Arm Raises

-5 arm raises

-Inhale raise arms up towards the ceiling, exhale slowly lower arms down toward the floor.

- Arm raises increase mobility in the upper back and shoulders, increase strength in core, upper back and shoulders and work with the breath to find coordination in movement.

\section{Seated Arm Raise Hold}

-Hold arms above head reaching directly up toward the ceiling for 5 breaths. -Holding the arms overhead increases mobility in the upper back and shoulders, increase strength in core, upper back and shoulders, builds stamina.

\section{Seated Forward Fold}

-Reach forward toward your toes. Relax the head and neck. Hold in this forward fold for 10 breaths.

-Seated forward fold stretches hamstrings, increasing flexibility, lengthens the spine, also is a good pose to slow the heart rate, reduce anxiety and alleviate insomnia. 


\section{Seated Twist}

-Inhale lengthen spine upwards, Exhale twist deeper. Hold each side for 5 breaths. -Twisting helps to regulate digestion, create mobility in the spine and detox the body.

6. Practice Sitting Up - (Transitions)

-Practice 5 times.

-Lay down on back, then with assistance sit up fully using your core to lift your body.

-Sitting up increases core strength, arm strength and mobility helping to ease transitions.

\section{Prone}

\section{Sphinx Pose}

-Hold yourself up on elbows and forearms. Working with the neck and head. -Rotate the head right and left. 3 times each side and hold for 3 breaths each time. -Working with the neck in sphinx pose increases strength and mobility in the cervical spine

\section{Cobra Pose}

-Practice 5 times.

-With forearms on the floor, press feet and legs down into the floor. Inhale lift the head and chest up off the floor using spine and neck strength, exhale lower down to the floor.

-Cobra increases spine and neck strength, pressure on the belly also helps to stimulate digestion, strengthens inner thighs and legs.

\section{Half Pigeon}

-Hold each side for 10 breaths.

-With assistance, subject will be placed into and out of this pose.

-Half pigeon stretches the gluteus maximus and hip joint

With assistance transfer to supine position. 
Supine

10. Happy Baby Pose

-Hold for 5 breaths.

-With assistance, the legs will be bent and brought into a frog position with the knees pointing towards the armpits and the souls of the feet pointing up towards the ceiling.

-Happy baby pose opens hips and increases flexibility in the hip joint.

\section{Supine Twist}

-Hold each side for 5 breaths.

-Hug right knee in toward the chest then twist the torso open to the left, pulling the right knee toward the left side of the body. Switch sides.

-Supine twist rinses out the spine and helps to regulate digestion.

12. Relaxation / Savasana

-Spend 5 minutes with the eyes closed keeping a slow steady breathe. Allow the body and mind to fully relax and let go. 


\section{APPENDIX E}

Photos of Yoga Asanas in Routine

1. Seated Breathing

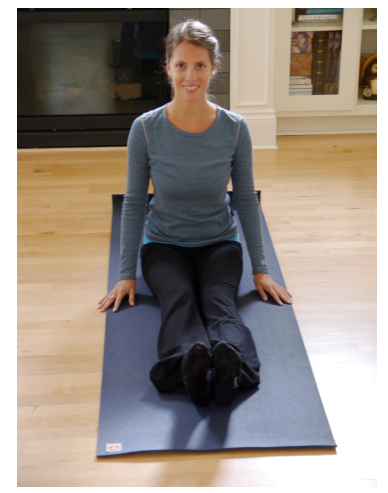

2. Seated Arm Raises / 3. Arm Raise Hold

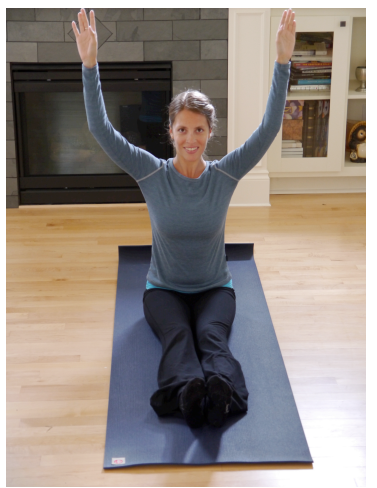

4. Seated Forward Fold

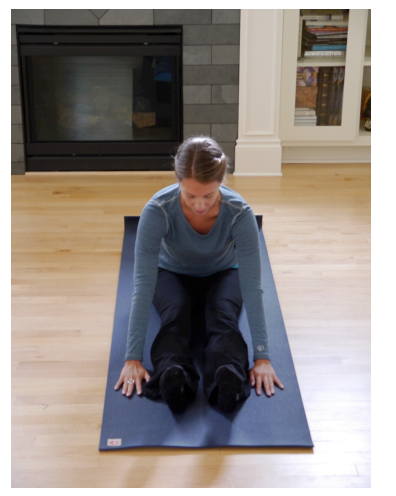

5. Seated Twist

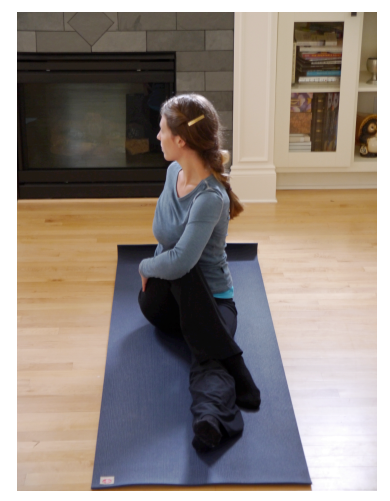

6. Practice Sitting Up - Transition (Not Pictured) 
7. Sphinx Pose

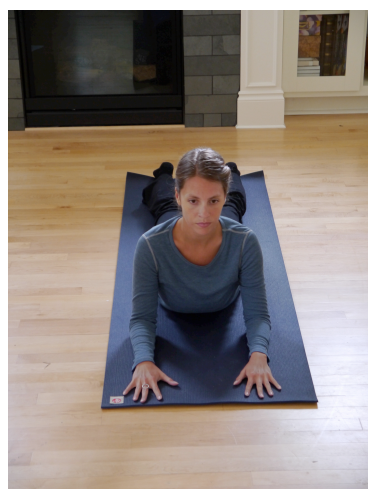

\section{Cobra Pose}

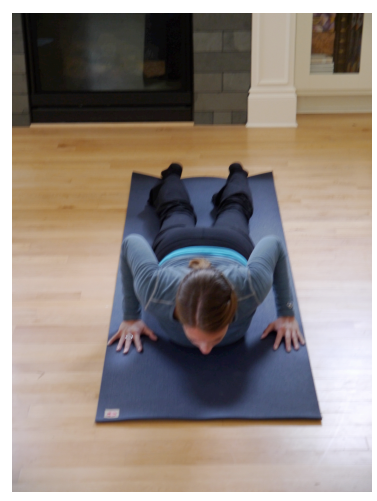

10. Happy Baby Pose

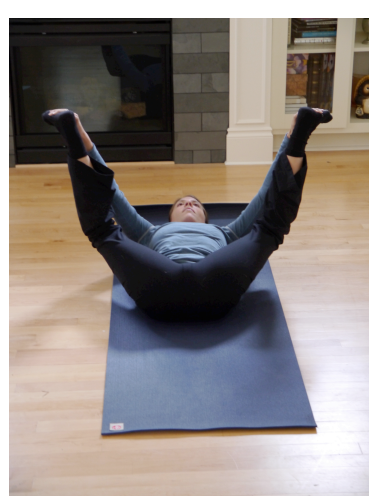

7. Sphinx with Head Rotation

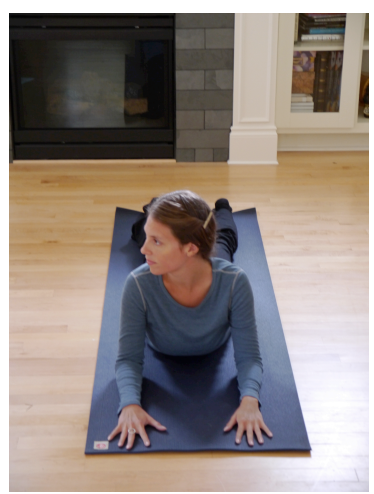

9. Half Pigeon

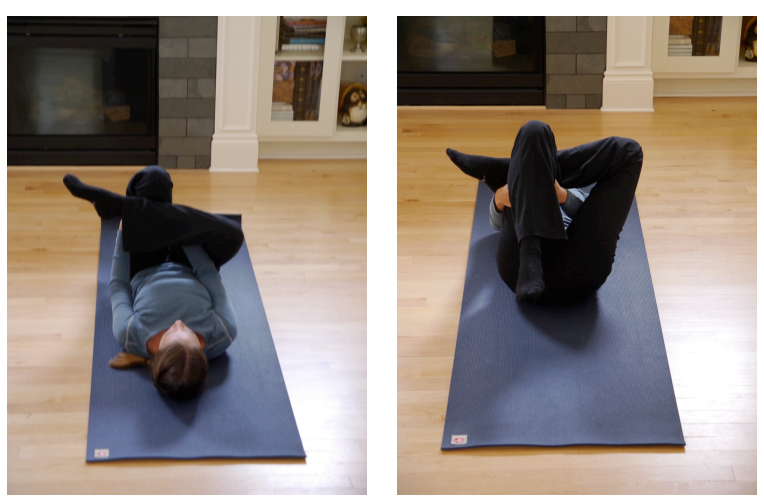

11. Supine Twist

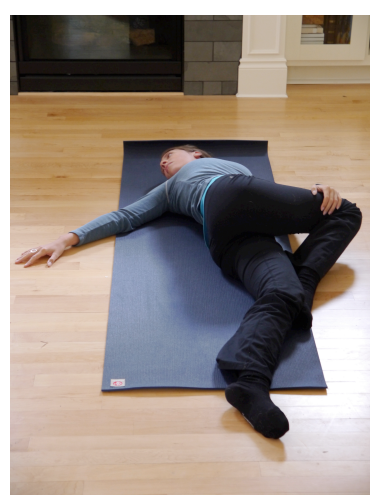


12. Savasana / Relaxation

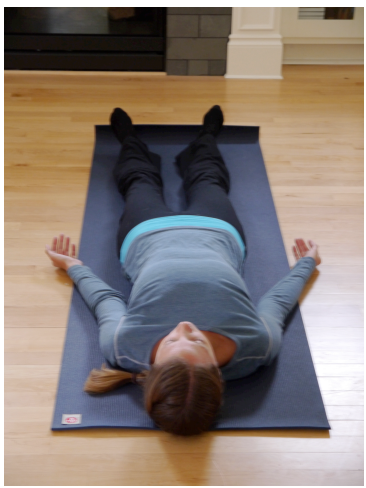




\section{APPENDIX F \\ Documented Observations from the Subject}

$3 / 25 / 12$

Pre lesson: I have pain in my hips and left knee, pain in right side rib and tightness in the shoulders.

Post lesson: I feel less tight in shoulders and sides, right side rib still hurts but feel some relief, almost less tight. Worked all day, bladder seemed irritated, drank last night, worked on Backbones after work, going to expo in LA on Thursday.

$3 / 27 / 12$

Pre lesson: Didn't sleep well, I was sore after $1^{\text {st }}$ session, used the Lokomat today for 35 minutes. Have a weird feeling in the my left knee and hip. My hips are sore, probably from the Lokomat.

Post lesson: Practice felt easier and I felt like I had more control today.

$3 / 28 / 12$

Felt relaxed after. Slept well and got rested even though I had to get up early for a flight. $4 / 4 / 2012$

Super relaxed day. No work today

$4 / 5 / 2012$

My control when an airplane lands has improved by contracting my core and deepening my breath. Also, my cobra was higher and felt easier. When my legs were inverted at the end of the practice I had tingling in my quadraceps and hips. I also felt more control when doing the arm raises and they felt easier. My back felt really arched and tight. 4/7/2012

On Friday, a trainer at ADAPT commented on my breathing and control during our exercise session. My morning started off with low blood pressure because I had not drank any water. I held cobra for a pretty long time and held it higher than before.

$4 / 8 / 2012$

I slept on my back for a long time and it felt good on my back and hips. I have been having some cramps because I will be getting my period soon and I am nervous about quitting my job. 
$4 / 9 / 2012$

Craving more yoga. I miss it.

$4 / 10 / 2012$

I had trouble with my first breaths, my chest felt tight like my lungs didn't want to expand. I only drank a mug of water today. Slept well. Had a good poop, my bowels are working well. I feel bloated because I am supposed to get my period.

$4 / 11 / 2012$

My period body aches have not been bad at all. I held cobra for a long time and held it pretty high. I could feel burning in the muscles of my back and sides. Breathing was much better today.

$4 / 14 / 2012$

My left hip is really tight and it felt somewhat better after. I felt very achy on Thursday night.

$4 / 17 / 2012$

Felt really out of it and tired.

$4 / 18 / 2012$

Tomorrow is my last day at work. I am happy because it was stressing me out to not be able to do Backbones.

$4 / 22 / 2012$

Nick was our guest today. I turned on my belly and did those exercises before we practiced the sit-ups and it felt better on my hips. I also lasted for 15 breaths with my arms up in the air in a high V. I could have gone longer. Nick says that my movements are more controlled and calculated since doing yoga and that I am using less momentum. Yes! I need to continue after the study my back is getting stronger.

$4 / 25 / 2012$

I had to reschedule, had bowel issues.

$4 / 27 / 2012$

I had a morning yoga session, which was nice and different. Felt a bit lightheaded. In the training session after I felt so energized and my body felt awake! I did some standing and lasted longer than usual without my blood pressure going down. My muscles all over felt very active. Awesome workout! 
$4 / 28 / 2012$

Last session. Felt very light headed all morning. Had to stop in the middle of arm raises, must have needed more water. 


\section{APPENDIX G}

\section{Interview Questions: Pre / Post Study}

\section{Please circle your response.}

1. In the past 2 weeks how often have you experienced insomnia (difficulty sleeping)?

$$
0 \quad 1-3 \quad 4-6 \quad 7-9 \quad 9+
$$

2. In the past 2 weeks how often has bladder control been an issue for you?

$$
0 \quad 1-3 \quad 4-6 \quad 7-9 \quad 9+
$$

3 . In the past 2 weeks how would you rate any muscle spasms you experience?

Extremely Intense - More than Normal - Neutral/Normal Spasms - Less Intense - NonExistent

4. In the past 2 weeks how would you rate any upper body pain you experience (head, neck, shoulders)?

No Pain Experienced- Mild - Discomforting - Distressing - Horrible - Excruciating

5. In the past 2 weeks how would you rate any mid-section pain you experience (chest, torso: including spine and digestive system)?

No Pain Experienced - Mild - Discomforting - Distressing - Horrible - Excruciating

6 . In the past 2 weeks how would you rate any lower body pain you experience (hips, legs, feet)?

No Pain Experienced - Mild - Discomforting - Distressing - Horrible - Excruciating

7. How would you describe your overall emotional state over the course of a day?

$$
\text { Depressed/Sad - Mellow/Calm - Happy/Energized - Happy/Calm }
$$

Combination of Highs and Lows

8. How much sensation can you feel in your lower body?

None - Very Little - Same amount of sensation as my upper body

9. Compared to a year ago, how would you describe sensation in your lower body?

Same as 1 year ago - Slight increase - Dramatic increase

10. How would you rate your mobility when transferring in and out of your chair?

Extremely difficult - Challenging - Neutral/Normal - Easier than usual - Extremely

Easy 
11. Would you describe your daily breathing as $?$

Always challenging - Sometimes challenging - Neutral - Easy - Extremely Easy

12. I feel strong. (True or False)

13. I know how to relax myself. (True or False)

For questions 14-19, please supply a short answer.

14. I think that practicing yoga regularly will ...

15. The thing that I notice most when I practice yoga is ...

16. Mentally yoga makes me feel ....

17. Emotionally yoga makes me feel .....

18. Physically yoga makes me feel .....

19. Please write any additional comments that you would like to share with the principal investigator. 


\section{APPENDIX H}

$\begin{array}{lll}\text { Subject Responses to Interview } & \text { Questions Pre and Post Study } \\ \text { Question } & \text { Pre Study } & \text { Post Study } \\ \mathbf{1} & 4 \text { to } 6 & 1 \text { to } 3 \\ \mathbf{2} & 1 \text { to } 3 & 0 \\ \mathbf{3} & \text { neutral/normal spasms } & \text { less intense } \\ \mathbf{4} & \text { discomforting } & \text { mild } \\ \mathbf{5} & \text { distressing } & \text { discomforting } \\ \mathbf{6} & \text { distressing } & \text { discomforting } \\ \mathbf{7} & \text { mellow/calm } & \text { happy/calm } \\ \mathbf{8} & \text { same as 1 year ago } & \text { a slight increase } \\ \mathbf{9} & \text { extremely difficult } & \text { challenging } \\ \mathbf{1 0} & \text { sometimes challenging } & \text { sometimes challenging } \\ \mathbf{1 1} & \text { FALSE } & \text { TRUE } \\ \mathbf{1 2} & \text { TRUE } & \text { TRUE }\end{array}$

13. I think that practicing yoga will ...

Pre Study: relax my body, make me feel good, make me feel more stable

Post Study: make me calm, relaxed, confident

14. The thing that I notice when I practice yoga is ...

Pre Study: less pain, less tightness

Post Study: confidence, less pain

15. Mentally yoga makes me feel...

Pre Study: focused on what's important

Post Study: calm, a time to get away from my day and then I am more focused when I get back to work 
16. Emotionally yoga makes me feel ...

Pre Study: self-relieved, calm, happy, accepting

Post Study: confident, sexy-desireable, comfortable with my body, accepting

17. Physically yoga makes me feel ...

Pre Study: less pain, relaxed, elongated

Post Study: less pain, better muscle function and activity when I stand, stronger, focused, calculated movement

18. Any additional comments for the principal investigator ...

Pre Study: Super excited to see how constant yoga sessions can affect my body, sensation and physical ability.

Post Study: I'm more aware of movement, spacially where my body is. Breathing helps during bowel routine and bladder control. Breathing techniques help with raising blood pressure when it is low. Thanks! 


\section{APPENDIX I}

\section{Perceived Stress Scale}

\section{Perceived Stress Scale}

\section{Sheldon Cohen}

The Percerved Stress Scale (PSS) is the most widely used psychological instrument for measuring the perception of stress. It is a measure of the degree to which situations in one's life are appraised as stressful. Items were designed to tap how unpredictable, uncontrollable, and overloaded respondents find their lives. The scale also includes a number of direct queries about current levels of experienced stress. The PSS was designed for use in community samples with at least a junior high school education. The items are easy to understand, and the response alternatives are simple to grasp Moreover, the questions are of a general nature and hence are relatively free of content specific to any subpopulation group. The questions in the PSS ask about feelings and thoughts during the last month. In each case, respondents are asked how often they felt a certain way.

Evidence for Validity: Higher PSS scores were associated with (for example):

- failure to quit smoking

- failure among diabetics to control blood sugar levels

- greater vulnerability to stressful life-event-elicited depressive symptoms

- more colds

Health status relationship to PSS: Cohen et al. (1988) show correlations with PSS and: Stress Measures, SelfReported Health and Health Services Measures, Health Behavior Measures, Smoking Status, Help Seeking Behavior.

Temporal Nature: Because levels of appraised stress should be influenced by daily hassles, major events, and changes in coping resources, predictive validity of the PSS is expected to fall off rapidly after four to eight weeks.

Scoring: PSS scores are obtained by reversing responses (e.g., $0=4,1=3,2=2,3=1 \& 4=0$ ) to the four positively stated items (items $4,5,7, \& 8$ ) and then summing across all scale items. A short 4 item scale can be made from questions $2,4,5$ and 10 of the PSS 10 item scale.

Norm Groups: L. Harris Poll gathered information on 2,3B7 respondents in the U.S.

Norm Table for the PSS 10 item inventory

\begin{tabular}{l|r|r|r}
\hline Category & N & Mean & S.D. \\
\hline $\begin{array}{l}\text { Gender } \\
\text { Male }\end{array}$ & 926 & 12.1 & 5.9 \\
$\quad \begin{aligned} \text { Female } \\
\text { Age }\end{aligned}$ & 1406 & 13.7 & 6.6 \\
$18-29$ & 645 & 14.2 & 6.2 \\
$30-44$ & 750 & 13.0 & 6.2 \\
$45-54$ & 285 & 12.6 & 6.1 \\
$55-64$ & 282 & 11.9 & 6.9 \\
$65 \&$ older & 296 & 12.0 & 6.3 \\
Race & & & \\
white & 1924 & 12.8 & 6.2 \\
Hispanic & 98 & 14.0 & 6.9 \\
black & 176 & 14.7 & 7.2 \\
$\quad$ other minority & 50 & 14.1 & 5.0 \\
\hline
\end{tabular}

Copyright (1994. By Sheldon Cohen. All rights reserved. 


\section{Perceived Stress Scale}

The questions in this scale ask you about your feelings and thoughts during the last month. In each case, you will be asked to indicate by circling how often you felt or thought a certain way.

Name

Date

Age Gender (Circle): M F Other

\section{$0=$ Never $\quad 1=$ Almost Never $\quad 2$ = Sometimes 3 = Fairly Often $\quad 4=$ Very Often}

1. In the last month, how often have you been upset because of something that happened unexpectedly?

$\begin{array}{lllll}0 & 1 & 2 & 3 & 4\end{array}$

2. In the last month, how often have you felt that you were unable to control the important things in your life?

$\begin{array}{lllll}0 & 1 & 2 & 3 & 4\end{array}$

3. In the last month, how often have you felt nervous and "stressed"? $\begin{array}{lllll}0 & 1 & 2 & 3 & 4\end{array}$

4. In the last month, how often have you felt confident about your ability to handle your personal problems?

$\begin{array}{lllll}0 & 1 & 2 & 3 & 4\end{array}$

5. In the last month, how often have you felt that things were going your way?

$\begin{array}{lllll}0 & 1 & 2 & 3 & 4 \\ 0 & 1 & 2 & 3 & 4 \\ 0 & 1 & 2 & 3 & 4 \\ 0 & 1 & 2 & 3 & 4 \\ 0 & 1 & 2 & 3 & 4 \\ 0 & 1 & 2 & 3 & 4\end{array}$

6. In the last month, how often have you found that you could not cope with all the things that you had to do?

In the last month, how often have you been able to control irritations in your life?

8. In the last month, how often have you felt that you were on top of things?..

9. In the last month, how often have you been angered because of things that were outside of your control?

10. In the last month, how often have you felt difficulties were piling up so high that you could not overcome them?

Please feel free to use the Perceived Stress Scale for your research.

\section{Mind Garden, Inc. \\ info@mindgarden.com www.mindgarden.com}

\section{References}

The PSS Scale is reprinted with permission of the American Scciological Asscciation, from Cohen, S., Kamarck, T., and Mermelstein. R (1983). A global measure of perceived stress. Joumgl of Health and Social Behavior, 24, 386-396.

Cohen, S. and Wiliamson, G. Perceived Stress in a Probability Sample of the United Stases. Spacapan, S. and Oskamp, S. (Eds.) The Social Psychology of Heaith. Newbury Park, CA: Sage, 1988. 


\section{APPENDIX J}

\section{Modified SF-36 Questionnaire}

(Please circle your response)

For the purposes of this study the SF-36 questionnaire was shortened. The original contains 11 questions and has been cut down to 6 . No additional questions were added, and the questions that are included remain unchanged from the original survey.

1. In general, would you say your health is :

Excellent Very Good Good Fair Poor

2. Compared to one year ago, how would you rate your health in general now?

Much better now than one year ago

Somewhat better now than one year ago

About the same as one year ago

Somewhat worse now than one year ago

Much worse now than one year ago

3. During the past week, have you had any of the following problems with your work or other regular daily activities as a result of any emotional problems (such as feeling depressed or anxious)?

a. Cut down the amount of time you spent on work or other activities yes / no

b. Accomplished less than you would like

yes / no

c. Didn't do work for other activities as carefully as usual

yes / no

4. How much bodily pain have you had during the past week?

None Very Mild Mild Moderate Severe Very Severe

5. During the past week, how much did pain interfere with your normal work (including both work outside the home and housework)?

Not at all A little bit Moderately Quite a bit Extremely

6. These questions are about how you feel and how things have been with you during the past week. For each question, please give the one answer that comes closest to the way you have been feeling. How much of the time during the past week ...

a. Did you feel full of pep?

All of the time / Most of the time / Some of the time / A little of the time / None of the time

b. Have you been a very nervous person?

All of the time / Most of the time / Some of the time / A little of the time / None of the time 
c. Have you felt so down in the dumps that nothing could cheer you up?

All of the time / Most of the time / Some of the time / A little of the time / None of the time

d. Have you felt calm and peaceful?

All of the time / Most of the time / Some of the time / A little of the time / None of the time

e. Did you have a lot of energy?

All of the time / Most of the time / Some of the time / A little of the time / None of the time

f. Have you felt downhearted and blue?

All of the time / Most of the time / Some of the time / A little of the time / None of the time

g. Did you feel worn out?

All of the time / Most of the time / Some of the time / A little of the time / None of the time

h. Have you been a happy person?

All of the time / Most of the time / Some of the time / A little of the time / None of the time i. Did you feel tired?

All of the time / Most of the time / Some of the time / A little of the time / None of the time 